www.jmscr.igmpublication.org

Impact Factor (SJIF): 6.379

Index Copernicus Value: 79.54

ISSN (e)-2347-176x ISSN (p) 2455-0450

crossrefDOI: https://dx.doi.org/10.18535/jmscr/v6i8.22

Journal Of Medical Science And Clinical Research

\title{
Significance of Diagnostic Colposcopic Evaluation in Cases with Abnormal pap smear
}

\author{
Authors \\ Dr Urvashi ${ }^{1}$, Dr Mukesh Chandra ${ }^{2}$, Dr Rajmani ${ }^{3}$ \\ ${ }^{1}$ Assistant Professor, Department of Obs \& Gynae, S.M.S. Medical College Jaipur \\ Mob-9928810030 Email-drrajmani6@ gmail.com \\ ${ }^{2}$ Professor, Department of Obs \& Gynae, S.N. Medical College Agra \\ ${ }^{3}$ Professor, Department of Medicine, J.L.N. Medical College Ajmer \\ Corresponding Author \\ Dr Rajmani
}

Professor, Department of Medicine, J.L.N. Medical College Ajmer, 302004, Rajasthan India

Mob-9829328228, Email: drrajmani6@gmail.com

\begin{abstract}
Introduction: Cervical cancer is the most common form of cancer in women in developing countries and the second most common form of the cancer in women in the world as a whole. India accounts for $18 \%$ of them. As primary prevention is the ultimate objective in the control of malignancy, hence specific screening and early detection have to be primary measures. The simultaneous use of pap smear and colposcopic screening has been shown to increase cervical cancer detection.
\end{abstract}

Aims and Objectives: To compare and correlate the abnormal areas and pap smear with colposcopy. and Colposcopic directed biopsies

Material and Methods: Present study was conducted on 100 married women more than 27 years of age attending the outpatient department of obstetrics and gynaecology of S. N. Medical college Agra and S M S Medical college Jaipur.

All these clients were screened by pap smear and coposcopy. Colposcopic directed biopsy was done in cases with abnormal colposcopic findings, naked eye appearance of unhealthy cervix, or symptomatic persistent inflammatory smear. Pap smear was taken in all cases.

Observations: In our study, sensitivity of pap smear was low but specificity was high. Correlation between pap smear and histology was 82.2\%. Specificity of colposcopy was not as good as sensitivity. Correlation between colposcopy and histology was $84.44 \%$. Accuracy of pap smear and colposcopy individually was approximately same ( $82.22 \%$ and $84.44 \%$ respectively). Accuracy was increased when both tests were used simultaneously (95.56\%).

Conclusion: Colposcopic examination is an accurate method of evaluation of patients with abnormal pap smear and both are supplement to each other in the diagnosis of cervical neoplasia. Both tests will become highly accurate when combined with colposcopic directed biopsy.

\section{Introduction}

Cervical cancer is the most common form of cancer in women in developing countries and the second most common form of the cancer in women in the world as a whole [parkin et al]. India accounts for $18 \%$ of them [Algotar k et al]. 
Progressive degree of cervical dysplasia precede the occurrence of the invasive cervical cancer. The annual progression rate from dysplasia to cervical carcinoma is $5-6.4 \%$.

As primary prevention is the ultimate objective in the control of malignancy, hence specific screening and early detection have to be primary measures. The papanicolaou (pap) smear is the primary screening tool for cervical intra- epithelial neoplasia(CIN) and invasive cancer of the cervix. The sensitivity and specificity of pap smear is $57 \%$ and $76 \%$ respectively [mertulas et al]. Colposcopy is the diagnostic test to evaluate patients with an abnormal pap smear or abnormal looking cervix. It entails the use of a field microscope to examine the cervix. Colposcopic directed biopsies of all lesions and specifically the most severe lesions are performed. This leads to tissue diagnosis of the disease present and greatly reduces the necessity of multiple biopsies. The simultaneous use of pap smear and colposcopic screening has been shown to increase cervical cancer detection [Tawa et al].

\section{Aims and Objectives}

To compare and correlate the abnormal areas and pap smear with colposcopy. and Colposcopic directed biopsies

\section{Material and Methods}

Present study was conducted on 100 married women more than 27 years of age attending the outpatient department of obstetrics and gynaecology of S. N. Medical College Agra and S M S Medical College Jaipur.

All these clients were screened by pap smear and coposcopy. Colposcopic directed biopsy was done in cases with abnormal colposcopic findings, naked eye appearance of unhealthy cervix, or symptomatic persistent inflammatory smear. Pap smear was taken in all cases.

Pap Smear Grading (Gehlot M . et al)

\begin{tabular}{|l|l|}
\hline Grade & finding on pap smear \\
\hline 1 & Normal smear \\
\hline 2 & Inflammatory smear \\
\hline 3 & Mild dysplasia or CIN -1 \\
\hline
\end{tabular}

\begin{tabular}{|l|l|}
\hline 4 & $\begin{array}{l}\text { Moderate and severe dysplasia } \\
\text { or CIN 2 and CIN 3 }\end{array}$ \\
\hline 5 & Malignant cells \\
\hline
\end{tabular}

\section{Indications of Colposcopy}

1) Suspicious symptoms like white discharge per vaginum, abnormal bleeding per vaginum.

2) Suspicious cervix (erosion, hypertrophied cervix, bleeds on touch).

3) Abnormal pap smear.

Colposcopy was called satisfactory when the entire transformation zone, including the entire squamocolumnar junction was visualised.

A loop biopsy was taken from the areas with abnormal colposcopic findings.

Cervical biopsy was colposcopic directed and taken from the most suspicious areas .Pictures of the lesions and biopsy sites were photographed, drawn and labelled.

\section{Colposcopic Grading (Algotar K et al)}

\begin{tabular}{|l|l|}
\hline Grade & Colposcopic Finding \\
\hline $\mathbf{1}$ & $\begin{array}{l}\text { Acetowhite epithelium with regular pattern of } \\
\text { fine calibre vessels }\end{array}$ \\
\hline $\mathbf{2}$ & $\begin{array}{l}\text { Acetowhite epithelium with an irregular pattern } \\
\text { of coarse calibre vessels }\end{array}$ \\
\hline $\mathbf{3}$ & $\begin{array}{l}\text { Acetowhite epithelium with an irregular pattern } \\
\text { of coarse calibre vessels and irregular surface } \\
\text { contour }\end{array}$ \\
\hline
\end{tabular}

Colposcopic grading correlated with histopathology (Algotar K et al)

\begin{tabular}{|l|l|}
\hline Colposcopic grading & correlated with histology \\
\hline 1 & Normal to CIN-1 ( mild dysplasia) \\
\hline 2 & CIN-2 ( moderate dysplasia) \\
\hline 3 & $\begin{array}{l}\text { CIN-3 (severe dysplasia) early } \\
\text { indication to frank malignancy }\end{array}$ \\
\hline
\end{tabular}

\section{Observations}

In our study, minimum age of the patients was 28 years and the oldest one was of 67 years of age. Maximum number of patients were in the fourth decade. Most of the patients were multiparous and only $2 \%$ were nulliparous. Maximum number of patients seen were para 2 .

The most common presenting symptom was white discharge per vaginum. This was present either alone or in combination with other symptoms like 
pain in abdomen, menorrhagia , post menopausal and postcoital bleeding, intermenstrual bleeding and irregular periods. 82 patients had more than one complaints.

Majority of patients on perspeculum examination of the cervix revealed cervical erosion in 78 patients while 37 had hypertrophied cervix , 9 had bleeding on touch and 4 had small polypoidal growth .9 patients had healthy cervix while 3 had nabothian cysts.

Out of 100 patients, 10 patients had normal pap smears, 82 had inflammatory smears. Mild, moderate and severe dysplasia were present in 2,3, 1 patients, respectively. 2 had squamous cell carcinoma.

All patients underwent colposcopic examination. Table 2 showing that out of 100 cases, 45 had abnormal examination. Aceto-white areas were seen in 45 cases and maximum numbers (22) of areas were present on anterior lip of cervix . Aceto-white areas with mild, moderate and high intensity were found in 37, 4 and 4 cases, respectively. Most of the high intensity areas related to malignant lesions. Coarse calibre vessels were found in 18 cases, in which 10 cases showed mosaic pattern and 8 punctate pattern. 3 patients had both pattern of coarse calibre vessels and were associated with dysplastic and malignant lesions. Irregular surface contour were found in 4 cases and most were associated with malignant changes. 6 cases showed iodine negative areas and all associated with dysplastic and malignant lesions. Grade -1 colposcopy was present in 30 cases while grade 2 and grade- 3 colposcopy were present in 11 and 4 cases, respectively.

Table 4 show that out of 100 cases, 45 cases underwent colposcopic guided biopsies of those which revealed abnormal colposcopic findings. 4 cases had normal biopsy, 29 cases showed cervicits. Mild and moderate dysplasia were present in 4 and 5 cases, respectively. Squamous cell carcinoma was found in 3 cases.

On correlating colposcopy with pap smear(table 5),55 patients with normal coposcopy had grade 1 (normal smear) and grade-2 (inflammatory) pap smear in 5 and 50 patients, respectively. 30 patients with grade- 1 colposcopy had grade- 1 and grade- 2 smear in 3 and 27 patients, respectively. In 11 patients with grade-2 colposcopy, 2 had grade-1 smear while 4 had grade-2, 2 had grade- 3 (mild dysplasia) and 3 had grade-4 (severe dysplasia) pap smear. In patients with grade-3 colposcopy, one had grade- 2 , one had grade- 4 and 2 had grade-5 (squamous cell carcinoma) pap smear.

On correlating colposcopy with cervical histopathology (table 6), patients with grade 1 colposcopy revealed normal histology in 2 cases and cervicitis in 28 cases. In grade- 2 colposcopy, 2 cases had normal histology while 4 had mild dysplasia (CIN-1) and 5 had moderate dysplasia (CIN-2). Out of 4 cases of grade- 3 colposcopy, 1 had cervicitis and 3 had squamous cell carcinoma on histology.

Table 7 showed that 2 patients with normal pap smear had mild dysplasia on biopsy and 1 patient had moderate dysplasia while 1 had normal biopsy. Out of 82 cases of grade 2 (inflammatory) pap smear, in 33 cases with abnormal colposcopic findings, colposcopic directed biopsy was done. In 1 case of grade 2 smear, mild dysplasia (CIN -I) was found on histology while 29 cases had cervicitis and 3 cases had normal histology. Mild dysplasia (CIN-I) was found on histology in 2 cases of grade 3 pap smear. 3 cases of grade 4 (Mod dysplasia) smear showed moderate dysplasia (CIN-II) on histology, however one case of grade 4 (severe dysplasia , CIN-3) showed squamous cell carcinoma on histology. 2 cases of squamous cell carcinoma on pap smear also had squamous cell carcinoma on histology.

Table 8 showed in 45 cases with abnormal colposcopic findings, 2 cases with grade-1 colposcopy and grade-1 (normal) pap smear had normal histology. 28 cases with grade-1 colposcopy and grade-2 (inflammatory) smear had cervicitis on histology. 2 cases with grade-2 colposcopy and grade-1 smear had normal histology. 2 cases with grade- 2 colposcopy and grade-3 smear had mild dysplasia. 2 cases with 
grade-2 colposcopy and grade- 2 smear had moderate dysplasia on histology while 3 cases with grade-2 colposcopy and grade- 4 smear (moderate dysplasia) had moderate dysplasia on histology. One case with grade-3 colposcopy and grade- 2 smear had cervicitis. One case with grade3 colposcopy and grade-4 (severe dysplasia) smear had squamous cell carcinoma. 2 cases with grade-3 colposcopy and grade-5 (squamous cell carcinoma) smear also had squamous cell carcinoma on histology.

Table No 1 Pap Smear Findings

\begin{tabular}{|l|c|}
\hline \multicolumn{1}{|c|}{ Pap smear findings } & No of patients \\
\hline Normal & 10 \\
\hline Inflammatory & 82 \\
\hline Mild dysplasia ( CIN-1) & 2 \\
\hline Moderate dysplasia (CIN-2) & 3 \\
\hline Severe dysplasia(CIN-3) & 1 \\
\hline Squamous cell carcinoma & 2 \\
\hline
\end{tabular}

Table No 2 Abnormal Colposcopic Examination

\begin{tabular}{|l|l|c|}
\hline \multicolumn{2}{|l|}{ Abnormal Colposcopic finding } & $\begin{array}{c}\text { No of } \\
\text { patients }\end{array}$ \\
\hline \multirow{2}{*}{ Acetowhite Areas } & Mild Intensity & 37 \\
\cline { 2 - 3 } & Moderate Intensity & 4 \\
\cline { 2 - 3 } & High Intensity & 4 \\
\hline \multirow{2}{*}{$\begin{array}{c}\text { Coarse calibre } \\
\text { vascular patterns }\end{array}$} & Mosaic pattern & 10 \\
\cline { 2 - 3 } Surface Contour & Punctate pattern & 8 \\
\cline { 2 - 3 } & Smooth & 96 \\
\cline { 2 - 3 } & Irregular & 6 \\
\hline Iodine negative areas & & 6 \\
\hline
\end{tabular}

Table No 3 Colposcopic Grading

\begin{tabular}{|l|c|}
\hline Colposcopic grading & no of patients \\
\hline Normal colposcopy & 55 \\
\hline $\begin{array}{l}\text { Grade 1 [acetowhite epithelium With regular } \\
\text { pattern of fine calibre }\end{array}$ & 30 \\
Vessels/ CIN-1 (mild dysplasia)] & 11 \\
\hline $\begin{array}{l}\text { Grade 2 [acetowhite epithelium } \\
\text { With irregular pattern of coarse } \\
\text { Calibre vessels / CIN-2 (moderate dysplasia )] }\end{array}$ \\
\hline $\begin{array}{l}\text { Grade 3 [Acetowhite epithelium with irregular } \\
\text { pattern of coarse calibre vessels and Irregular } \\
\text { contour of surface /CIN-3 (Severe dysplasia or } \\
\text { malignancy)] }\end{array}$ \\
\hline
\end{tabular}

Table No 4 Cervical Histopathology

\begin{tabular}{|l|c|c|}
\hline Histopathological findings & No of patients & $\%$ \\
\hline Normal & 4 & 8.89 \\
\hline Cervicitis & 29 & 64.44 \\
\hline Mild dysplasia ( CIN-1) & 4 & 8.89 \\
\hline Moderate dysplasia (CIN-2) & 5 & 11.11 \\
\hline Severe dysplasia(CIN-3) & 0 & 0 \\
\hline Squamous cell carcinoma & 3 & 6.67 \\
\hline
\end{tabular}

Table No 5 Correlation of Colposcopy with Pap Smear

\begin{tabular}{|l|c|c|c|c|c|c|}
\hline \multirow{2}{*}{$\begin{array}{l}\text { COLPOSCOPIC } \\
\text { GRADING }\end{array}$} & \multicolumn{7}{|c|}{ PAP SMEAR GRADING } & Total \\
\cline { 2 - 7 }$n$ & Grade I & Grade II & Grade III & Grade IV & Grade V & \\
\hline Normal & 5 & 50 & 0 & 0 & 0 & 55 \\
\hline Grade I & 3 & 27 & 0 & 0 & 0 & 30 \\
\hline Grade II & 2 & 4 & 2 & 3 & 0 & 11 \\
\hline Grade III & 0 & 1 & 0 & 1 & 2 & 4 \\
\hline
\end{tabular}

Table No 6 Correlation of Colposcopy with Cervical Histopathology

\begin{tabular}{|l|c|c|c|c|c|c|c|c|}
\hline \multirow{2}{*}{$\begin{array}{l}\text { COLPOSCOPIC } \\
\text { GRADING }\end{array}$} & $\begin{array}{c}|c| \\
\text { Biopsy not } \\
\text { done }\end{array}$ & Normal & Cervicitis & CIN I & CIN II & CIN III & $\begin{array}{c}\text { Squamous } \\
\text { cell carci. }\end{array}$ & \\
\hline Normal & 55 & 0 & 0 & 0 & 0 & 0 & 0 & 55 \\
\hline Grade I & 0 & 2 & 28 & 0 & 0 & 0 & 0 & 30 \\
\hline Grade II & 0 & 2 & 0 & 4 & 5 & 0 & 0 & 11 \\
\hline Grade III & 0 & 0 & 1 & 0 & 0 & 0 & 3 & 4 \\
\hline
\end{tabular}


Table No 7 Correlation of Pap Smear with Cervical Histopathology

\begin{tabular}{|l|c|c|c|c|c|c|c|c|}
\hline Pap smear & \multicolumn{7}{|c|}{ Histopathology } & Total \\
\cline { 2 - 9 } & $\begin{array}{c}\text { Biopsy } \\
\text { not } \\
\text { done }\end{array}$ & Normal & Cervicitis & CIN I & CIN II & CIN III & $\begin{array}{c}\text { Squamous } \\
\text { cell carci. }\end{array}$ & \\
\hline Grade I (Normal) & 6 & 1 & 0 & 2 & 1 & 0 & 0 & 10 \\
\hline Grade II (Inflammatory) & 49 & 3 & 29 & 1 & 0 & 0 & 0 & 82 \\
\hline Grade III (Mild CIN-I) & 0 & 0 & 0 & 2 & 0 & 0 & 0 & 2 \\
\hline $\begin{array}{l}\text { Grade IV (Mod and severe } \\
\text { dysplasia /CIN-II \& III) }\end{array}$ & 0 & 0 & 0 & 0 & 3 & 0 & 1 & 4 \\
\hline $\begin{array}{l}\text { Grade V (Squamous cell } \\
\text { carcinoma) }\end{array}$ & 0 & 0 & 0 & 0 & 0 & 0 & 2 & 2 \\
\hline
\end{tabular}

Table No 8 Correlation Of Abnormal Colposcopic Findings With Pap Smear And Cervical Histopathology

\begin{tabular}{|l|c|c|}
\hline $\begin{array}{l}\text { Colposcopic grading } \\
\text { (number of Patient) }\end{array}$ & Pap smear findings (number of Patient) & Histopathology (number of Patient) \\
\hline Grade I [2] & Grade I [2] & Normal Histology [2] \\
\hline Grade I [28] & Grade I [28] & Cervicitis [28] \\
\hline Grade II [2] & Grade I [2] & Mild dysplasia [2] \\
\hline Grade II [2] & Grade II [2] & Moderate dysplasia [2] \\
\hline Grade II [2] & Grade II [2] & Mild dysplasia [2] \\
\hline Grade II [2] & Grade III [2] & Moderate dysplasia [3] \\
\hline Grade II [3] 3$]$ & Grade IV [3] & Cervicitis [1] \\
\hline Grade III [1] & Grade II [1] & Squamous cell carci. [1] \\
\hline Grade II [1] & Grade IV [1] & Squamous cell carci. [2] \\
\hline Grade III [2] & Grade V [2] \\
\hline
\end{tabular}

\section{Discussion}

Cytological screening has significantly changed the detection of cervical carcinoma. Colposcopic evaluation of these patients is a further step in the detection of cervical carcinoma in its earliest stage. Present study was undertaken to find out the incidence of abnormal pap smear and its correlation with colposcopy.

Our study showed the mean age of dysplasia and malignancy to be 44.5 years. The mean age in our study is higher than mean age in other study. The difference can be attributed to lack of awareness and non availability of screening programme.

In the present study, incidence of abnormal pap smear with dysplasia and malignancy was 8 per 100 patients. Neighbor et al, Baram et al and Fragoyannis et al showed the incidence of 15,17 and 31 per 1000 patients, respectively. In our study, higher incidence of abnormal pap smear has been observed. Although, there is no definite reason for this increase in incidence. There are few factors which can be considered like this study was hospital based and not general survey of normal population as in other studies. Another reason is increasing numbers of women are now having routine pap smear examination and this results in an increased rate of detection of cervical carcinoma.

Acetowhite epithelium with abnormal vascularity was usually associated with dysplasia and those cases who had irregular surface contour along with abnormal vascularity were significantly malignant. All the patients with abnormal biopsy report had abnormal colposcopic findings. Hence the sensitivity of colposcopy is $100 \%$ in our study. Iyer et al, Scott et al, Staff et al, Richardreid et al and Donotive et al also had the similar sensitivity (87\%, 90\%, 91.2\%, 97\% and 98\%, respectively.). However, 7 cases those underwent colposcopic guided biopsy showed false positive findings. 2 and 4 cases with grade 2 colposcopy had normal histology and mild dysplasia, respectively. One case with grade 3 colposcopy had cervicitis on histology. Thus, specificity of colposcopy was not as good as sensitivity.

In present study, the correlation between colposcopy and histology was $84.44 \%$. Other workers also showed similar findings (Algotar et 
al, Selim et al, Matingly et al and Adolf et al showed $83 \%, 83.5 \%, 85 \%$ and $85 \%$, respectively) . However, some other workers revealed higher correlations: Tovel (96.40\%), Gehlot $\mathrm{M}$ et al (93.33\%), Wills et al(92\%) and Agarwal et al (89.69\%).

In this study when comparing pap smear with cervical histology, 3 cases with grade 1(normal) pap smear had false negative findings (i.e. 2 cases had mild and 1 case had moderate dysplasia on histology.) while one case with normal pap smear also had normal histology . 3 cases with grade 2 (inflammatory) pap smear had false positive finding(i.e. normal histology) and one case had false negative finding (i e moderate dysplasia) while 29 cases had cervicitis on histology. Both cases with grade 3(mild dysplasia) pap smear also had mild dysplasia on histology. all 3 cases with grade 4 (moderate dysplasia )pap smear also had moderate dysplasia on histology but 1 case with severe dysplasia on pap smear had false negative finding (i.e. there was squamous carcinoma on histology.). Both case with grade 5 (squamous cell carcinoma)on pap smear also had similar findings on histology. Thus sensitivity of pap smear is low (i e high false negativity rate) but specificity is high (i e low false positivity rate). Singh SL et al revealed that sensitivity and specificity of pap smear was low (20\%) and high (91.25\%), respectively .Our study found that the correlation between pap smear and histology is $82.2 \%$. Lazowski et al showed the similar correlation between pap smear and histology. Gehlot $\mathrm{M}$ et al and Telebian et al found $93.33 \%$ and $100 \%$ correlations, respectively. However, Algotar k et al revealed very low correlation.

In our study, correlation between abnormal colposcopy and abnormal pap smear was present in 43 out of 45 cases $(95.5 \%)$. Gehlot $\mathrm{M}$ et al revealed similar results as our study. They found 95.92\% correlation between colposcopy and abnormal pap smear. Sheshadri et al and Telebian et al showed $87.6 \%$ and $100 \%$ correlation, respectively.
Thus accuracy of pap smear and colposcopy individually was approximately same $(82.22 \%$ and $84.44 \%$ respectively). Accuracy was increased when both tests were used simultaneously (95.56\%).

Hence colposcopy and pap smear are not competitive but rather supplement each other in the diagnosis of cervical dysplasia and malignancy and this diagnosis will become highly accurate when these tests combined with colposcopic directed biopsy.

\section{Conclusion}

Colposcopic examination is an accurate method of evaluation of patients with abnormal pap smear and both are supplement to each other in the diagnosis of cervical neoplasia. Both tests will become highly accurate when combined with colposcopic directed biopsy.

\section{References}

1 Agarwal U, Kaur M, Kharakwal S: Role of cytology and colposcopicaly directed biopsies in various lesions of cervix. J Obs \& Gynaecology; 1989;39;548

2 Benedect JL, Anderson GH, Boyes DA. Colposcopic accuracy oin diagnosis of microinvasive and occult invasive carcinoma of cervix. J obs Gynae. 1985; $65 ; 557-562$.

3 Algotar K, Nalawade A, Sachdev S: Predictive value of colposcopy in cervical cancer screening. www.pubmed.com.

4 Gehlat M, Hooja N, Lakhiwal MK: correlation between colposcopy, cytology and histology incervical lesions. J Obstet Gynaecol Ind sep-oct 2001; 51(5); 180183

5 Lazowski MS, Mishriki Y, Telebian F: Acta cytol 1982;26;285

6 Neighbor RM, Newman RL: Incidence of cervical cancer in peri and postmenopausal women detected by pap smears. American J Obs and Gynae;1976;348-351 
7 Parkin DM. Estimate of the worldwide incidence of 25 major cancers in 1990. Int J Cancer 1999;80;827-841

8 Sheshadri L, Jairaj P, Krishnaswamy H: Ind J Cancer 1990;27(3);180

9 Singh SL, Dastur NA, Nanawati NA: A comparison of colposcopy and pap smear sensitivity, specificity and predictive value. Singapore Med J 2001, 42; 351-54

10 Staff A, Matingly RF: Colposcopic diagnosis of cervical neoplasia . J obs and Gynae 1973;20(4);168

11 Tawa K, Forshythe A, Cove JK, Saltz A. A comparision of the papanicolaou smear and cervicogram sensitivity, specificity and cost analysis. J Obs and Gynae ; 1988;71(2); 229-235

12 Telebian F, Shayan A: J obs and Gynae. 1977;6;49

13 Tovell HM, Banogan P, Nash AD. American J Obs Gynae. 1976;126;924

14 Wills S, Kanthamani PN. Histocytocolposcopic evaluation of 39 cases of postmenopausal bleeding. $\mathrm{J}$ Obs and Gynae Ind. 1991;41(1);99-102. 